\title{
Desain Sekuen Primer Dan Probe Quantitative Polymerase Chain Reaction Gen Spesifik RLEP Mycobacterium leprae
}

\author{
Asryadin \\ Mikrobiologi, UPT. Labkesda dan Pemeliharaan Alkes Kota Bima , Indonesia
}

\begin{tabular}{l} 
Article Info \\
\hline Article history: \\
Received Des $07^{\text {th }}, 2019$ \\
Revised Jan $18^{\text {th }}, 2020$ \\
Accepted Jan $20^{\text {th }}, 2020$ \\
\hline
\end{tabular}

\section{Keyword:}

Mycobacterium leprae

Primer and Probe

Gene sequence RLEP.

\begin{abstract}
Leprosy is an infectious disease caused by Mycobacterium leprae. Diagnosis of infections is important for the purpose of epidemiological studies, enforcement of diagnoses and administration of appropriate treatment therapy in infected patients. Early leprosy is difficult to diagnose only through clinical criteria because the coloring sensitivity is quite low. In addition, serological tests based on specific M. leprae antigens do not detect all clinical cases because most patients at the stage of paucibacillary $(P B)$ infection do not provide significant antibody response rates. The development of a method for detection of qPCR-based M. leprae targeting the RLEP gene sequence is important so that it can be used as a better alternative detection method. In this study, primers pair sequence and probes design used bioinformatics technology. The purpose of this study was to design a sequence of primers pair and probe for M. leprae based quantitative Polymerase Chain Reaction examination using the RLEP gene sequence. The study design was descriptive with a cross sectional study type. The data obtained were analyzed descriptively. The results were obtained: forward primer : 5'GTGCGGCCACATTGACCA-3'; reverse primer : 3'GGCTGTGCTGAAGGCGATATC-5' with 126 pairs of amplicons, and probe sequences : 5'-CGCCGACACCTCAAGGCCA-3'. The primers pair and probe sequences are eligible for $q-P C R$. Based on the results of the study it can be concluded that the sequence of primers and probes obtained can be used as a method of detecting M. Leprae using Quantitative Polymerase Chain Reaction.
\end{abstract}

Copyright () Jurnal Analis Medika Bio Sains All rights reserved.

\begin{abstract}
ABSTRAK
Kusta merupakan salah satu penyakit menular y ang disebabkan oleh Mycobacterium leprae. Diagnosis infeksi penting untuk tujuan studi epidemiologis, penegakan diagnosa serta pemberian terapi pengobatan yang tepat pada pasien terinfeksi. Kusta tahap awal sulit didiagnosis hanya melalui kriteria klinis karena sensitivitas pewarnaan yang cukup rendah. Selain itu, tes serologis berdasarkan antigen M. leprae spesifik tidak mendeteksi semua kasus klinis karena sebagian besar pasien pada tahap infeksi paucibacillary (PB) tidak memberikan tingkat respons antibodi yang signifikan. Pengembangan metode deteksi M. leprae berbasis qPCR dengan target sekuen gen RLEP penting dilakukan sehingga dapat dijadikan alternatif metode deteksi y ang lebih baik Dalam penelitian ini, desain sekuen pasangan primer dan probe menggunakan teknologi bioinformatika. Tujuan dari penelitian ini adalah untuk melakukan desain sekuen pasangan primer dan probe untuk pemeriksaan M. leprae berbasis kuantitatif Polymerase Chain Reaction menggunakan sekuen gen RLEP. Desain penelitian adalah deskriptif dengan jenis studi cross sectional. Sampel y ang digunakan dalam penelitian sebany ak 6 sekuen gen RLEP M. Leprae. Data y ang diperoleh dianalisis secara deskriptif. Hasil penelitian diperoleh : primer forward : 5'-GTGCGGCCACATTGACCA-3' '; primer reverse : 3'-GGCTGTGCTGAAGGCGATATC-5' 'dengan panjang amp likon 126 pasang basa, dan sekuen probe : 5' -CGCCGACACCTCAAGGCCA-3'. Sekuen pasangan primer dan probe memenuhi syarat untuk q-PCR. Berdasarkan hasil penelitian dapat dibuat simpulan bahwa sekuen pasangan primer dan probe y ang diperoleh dapat digunakan sebagai metode deteksi M. Leprae menggunakan Quantitative Poly merase Chain Reaction.
\end{abstract}

Kata Kunci : Mycobacterium leprae, Primer dan Probe, Sekuen Gen RLEP.

Copyright () Jurnal Analis Medika Bio Sains 


\section{Pendahuluan}

Penyakit kusta masih merupakan masalah kesehatan masyarakat di Indonesia, menurut data WHO (World Health Organization). Penyakit kusta merupakan salah satu penyakit tropis yang sering diabaikan, biasanya ditemukan 1:10.000 orang di sebagian besar populasi, dan sering dikaitkan dengan kemiskinan dan ketidakcukupan gizi serta higiene dan sanitasi yang buruk. Pada tahun 2015, jumlah kasus baru kusta di dunia sebesar 210.758 kasus dengan jumlah kasus tertinggi terjadi di Asia Tenggara yaitu sebanyak 156.118 kasus. Jumlah terbesar kasus baru kusta berasal dari Asia Tenggara, Amerika dan Afrika, Indonesia menduduki posisi nomor 3 dengan 16.825 kasus dengan angka kecacatan 6,82 orang per satu juta penduduk (Infodatin, 2018). Penanggulangan penyakit kusta secara efektif dan penegakan diagnosis sedini mungkin merupakan kunci utama untuk memberikan pengobatan secepatnya sehingga dapat memutus rantai penularan serta mencegah terjadinya kecacatan (Bakker et al., 2002).

Kusta merupakan salah satu penyakit menular yang disebabkan oleh Mycobacterium leprae, yaitu bakteri berbentuk basil tahan asam dan tidak dapat dikultur secara in vitro. Kusta tahap awal sulit didiagnosis hanya melalui kriteria klinis karena sensitivitas pewarnaan yang cukup rendah. Selain itu, tes serologis berdasarkan antigen M. leprae spesifik tidak mendeteksi semua kasus klinis karena sebagian bes ar pasien pada tahap infeksi paucibacillary (PB) tidak memberikan tingkat respon antibodi yang signifikan. Kelompok ini berpotensi terdiri dari pasien dengan beragam fitur klinis, bakteriologis, dan histopatologis. Seringkali, M. leprae tidak dapat dideteksi pada jaringan lesi awal, histopatologi bisa tidak spesifik, temuan klinis tidak meyakinkan, dan riwayat pasien bis a tidak dapat diandalkan sehingga membuat diagnosis kusta stadium dini sangat sulit (Yan, 2014).

Diagnosis infeksi penting untuk tujuan studi epidemiologis, penegakan diagnosa serta pemberian terapi pengobatan yang tepat pada pasien terinfeksi. Diagnosis kusta sampai saat ini masih menggunakan cara konvensional yang sudah dipergunakan sejak lama, yang didasarkan atas gambaran klinis, penemuan bakteriologis dan gambaran histopatologis. Meskipun untuk beberapa kasus kusta, diagnosisnya mudah tetapi untuk sebagian besar kasus kusta diagnosisnya masih sulit dan tidak memuaskan serta memerlukan waktu, pengalaman dan keahlian (Wardhana dkk., 2016). Pada saat ini telah dikembangkan teknik biologi molekuler yaitu Polymerase Chain Reaction (PCR) untuk mendeteksi DNA basil M. leprae yang memberikan hasilyang memuaskan (Arliny, 2003). Sebagian besar metode deteksi menargetkan sekuen non-coding repeating element (NCR) RLEP yang khas dalam whole genome M. leprae (Obraztsova, et al., 2018; Sandri, et al., 2018).

Quantitiative PCR (qPCR) merupakan variasi teknik PCR konvensional yang umumnya digunakan untuk melakukan kuantifikasi DNA atau RNA dengan primer dan probe yang akan menentukan keberhasilan deteksi spesifik fragmen PCR (Viljoen, et al., 2005). Pengembangan metode deteksi M. leprae berbasis qPCR dengan target sekuen gen RLEP penting dilakukan sehingga dapat dijadikan alte rnatif metode deteksi yang lebih baik. Pada penelitian dilakukan desain sekuen pasangan primer dan probe menggunakan teknologi bioinformatika (Baxevanis and Ouelette, 2000).

\section{Metode Penelitian}

Rancangan penelitian yang digunakan adalah penelitian deskriptif berbentuk studi potong lintang (cross sectional). Populasi adalah sekuen gen RLEP M. Leprae dengan jumlah sampel sebanyak 6 sekuen gen RLEP yang diunduh dari NCBI gene database. Teknik sampling yang digunakan berupa non random purpossive sampling. Penelitian dilakukan di UPT. Labkesda dan Pemeliharaaan Alkes Kota Bima pada bulan Desember tahun 2019. Analis a data hasil penelitian dilakukan secara deskriptif.

\section{Hasil Penelitian dan Pembahasan}

Urutan gen RLEP M. leprae yang diunduh dari NCBI nucleotide database GenPeptd diambil sebanyak 6 sekuen. RLEP dipilih karena merupakan gen dengan conserved region pada spesies M. leprae dan digunakan pada beberapa penelitian dengan PCR (Donoghue, 2001) serta merupakan sekuen non-coding repeating element (NCR) yang khas dalam whole genome M. leprae (Obraztsova, et al., 2018; Sandri, et al., 2018). Sekuen pasangan primer dan probe dapat dilihat pada gambar 1. 


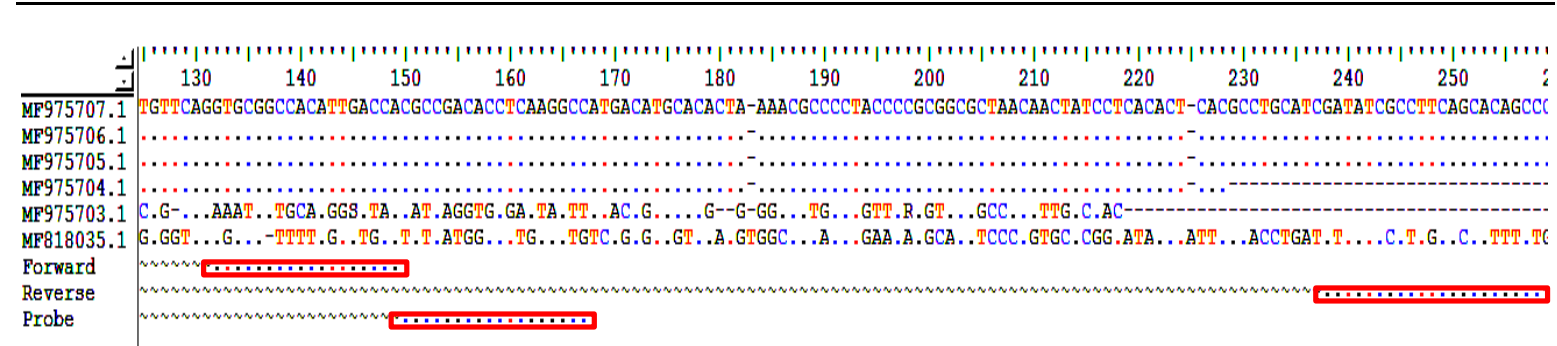

Gambar 1 MSA sekuen RLEP M. leprae dengan lokasi sekuen pasangan primer dan probe

Sekuen pasangan primer berada di posisi basa 132-149 (Forward) dan di basa 238-258 (Reverse) sedangkan probe berada di basa 150-168 (Refference sequence accesion number MF975707.1) dengan panjang amplikon 126 pasang basa dan dapat dilihat pada tabel 1 .

Tabel 1. Sekuen dan Hasil Uji Kualitas Pasangan Primer

\begin{tabular}{|c|c|c|c|c|c|c|}
\hline Pasangan Primer & $\begin{array}{l}\text { Panjang } \\
\text { Primer } \\
\text { (basa) }\end{array}$ & $\begin{array}{l}\text { fragmen } \\
\text { (bp) }\end{array}$ & $\begin{array}{l}\text { Kand } \\
\text { G C }(\%)\end{array}$ & $\begin{array}{l}\mathrm{Tm} \\
\left({ }^{\circ} \mathrm{C}\right)\end{array}$ & $\begin{array}{l}\text { Repeat } \\
\& \text { runs }\end{array}$ & $\begin{array}{l}\text { Struktur } \\
\text { sekunder }\end{array}$ \\
\hline $\begin{array}{l}\text { Forward } \\
\text { 5'GTGCGGCCACATTGACCA3' }\end{array}$ & 18 & \multirow{2}{*}{126} & 61 & 63 & - & \multirow[b]{2}{*}{ - } \\
\hline $\begin{array}{l}\text { Reverse } \\
\text { 3'GGCTGTGCTGAAGGCGATATC5' }\end{array}$ & 21 & & 57 & 63 & - & \\
\hline
\end{tabular}

Sekuen primer memiliki panjang 18 basa (forward) dan 21 basa (reverse). Panjang primer memenuhi persyaratan yaitu antara 18-28 basa (Viljoen, et al., 2005) karena jumlah basa pada sekuen primer menentukan efisiensi proses PCR (Hung and Zhiping, 2016). Pasangan primer memiliki komponen basa G dan C (GC content) $61 \%$ (forward) dan $57 \%$ (reverse), dimana jumlah ini memenuhi persyaratan komponen basa yaitu lebih dari 50\%. Komponen basa $\mathrm{G}$ dan $\mathrm{C}$ yang tinggi menentukan kestabilan primer karena memiliki 3 ikatan hidrogen (Viljoen, et al., 2005). Suhu leleh (Tm) primer sebesar $63,8^{\circ} \mathrm{C}$ (forward) dan $63,9^{\circ} \mathrm{C}$ (reverse) dengan perbedaan suhu $0,1^{\circ} \mathrm{C}$., Tm primer dan perbedaaan $\mathrm{Tm}$ pasangan primer memenuhi persyaratan yaitu suhu antara $52-60^{\circ} \mathrm{C}$ dengan perbedaan $\mathrm{Tm}$ tidak lebih dari $5^{\circ} \mathrm{C}$. Tm sen diri merupakan suhu yang digunakan sebagai acuan untuk menentukan suhu annealing (Ta) (Eling, et al., 2014)., apabila $\mathrm{Tm}$ lebih dari $65^{\circ} \mathrm{C}$ akan mengurangi efektifitas annealing sehingga amplifikasi DNA berjalan kurang baik. Selain itu, perbedaan Tm lebih dari $5^{\circ} \mathrm{C}$ menyebabkan proses amplifikasi kurang maksimal (Eling, et al., 2014).

GC clamp pada sekuen primer yang memenuhi persyaratan yaitu GC clamp terdapat pada ujung 3' sekuen primer reverse. GC clamp sebanyak 3 basa $\mathrm{C}$ sangat membantu terjadinya stabilitas ikatan antara primer dengan DNA template yang diperlukan untuk inisiasi polimerisasi DNA serta memperkuat proses annealing (Thermofisher, 2016). Selain itu, pasangan primer menghasilkan ukuran amplikon sepanjang 126 pasang basa, ukuran tersebut sudah sesuai dan dapat digunakan pada amplifikasi q-PCR karena panjang produk PCR ideal berkisar antara 50-150 pasang basa (Thermofisher, 2016). Sekuen pasangan primer juga memenuhi persyaratan komposisi basa karena tidak terjadi repeat dan runs komponen basa. Peng ulangan lebih dari 2 basa pada sekuen primer dapat menyebabkan terbentuknya struktur hairpin (Lorenz, 2012).

Struktur sekunder yaitu hairpin loop dan dimer (self, cross, heterodimer) tidak terbentuk pada sekuen pas angan primer ditandai dengan energi yang diperlukan untuk memecah struktur hairpin $(\Delta \mathrm{G})$ pada ujung 3' kurang dari $-3 \mathrm{kcal} / \mathrm{mol}$. Struktur sekunder perlu dihindari karena dapat menghambat proses penempelan primer yang menyebabkan berkurangnya efikasi PCR (Thermofisher, 2016). Sedangkan hasil uji kualtas sekuen probe dapat dilihat pada tabel 2 .

Tabel 2. Sekuen dan Hasil Uji Kualitas Probe sekuen RLEP M. Leprae

\begin{tabular}{|c|c|c|c|c|c|}
\hline Sekuen Probe & $\begin{array}{c}\text { Panjang } \\
\text { Primer } \\
\text { (basa) }\end{array}$ & $\begin{array}{c}\text { Kand } \\
\text { G C }(\%)\end{array}$ & Tm $\left({ }^{\circ} \mathrm{C}\right)$ & $\begin{array}{c}\text { Repeat \& } \\
\text { runs }\end{array}$ & $\begin{array}{c}\text { Struktur } \\
\text { sekunder }\end{array}$ \\
\hline 5' CGCCGACACCTCAAGGCCA '3 & 19 & 68 & 68 & - & - \\
\hline
\end{tabular}

Kualitas probe sekuen RLEP M. leprae memenuhi persyaratan untuk q-PCR (Gambar 4.2). Hal ini terlihat dari panjang sekuen probe (19 basa), komponen basa Gdan C (68\%) yang lebih tinggi dari komponen basa G dan C pasangan primer serta $\mathrm{Tm}\left(67,8^{\circ} \mathrm{C}\right)$ yang juga lebih tinggi dari Tm pasangan primer. Pada Sekuen probe juga tidak terjadi pengulangan 2 basa lebih dari 4 kali dan tidak terjadi pengulangan 1 basa lebih dari 4 kali serta tidak terbentuk struktur sekunder yang dapat mempengaruhi hasil amplifikasi q-PCR. 
Berdasarkan pengujian kemungkinan terjadinya reaksi silang (avoid cross homology) menggunakan primer BLAST NCBI, sekuen pasangan primer maupun probe menunjukkan homologi $100 \%$ dengan M. leprae yang dapat dilihat pada gambar 2 sampai dengan gambar.4.

\begin{tabular}{|c|c|c|c|c|c|c|c|}
\hline & Description & $\left|\begin{array}{c|}\text { Max } \\
\text { score }\end{array}\right|$ & $\mid$\begin{tabular}{c|} 
Total \\
score
\end{tabular} & \begin{tabular}{|l} 
Query \\
cover
\end{tabular} & $\left|\begin{array}{c}E \\
\text { value }\end{array}\right|$ & Ident & Accession \\
\hline$\square$ & Mycobacterium leprae clone $\$ 473$ Rlep repeat region & 36.2 & 36.2 & $100 \%$ & 5.1 & $100.00 \%$ & MF818035.1 \\
\hline$\square$ & Mycobacterium leprae strain MRHRU-235-G chromosome, complete genome & 36.2 & 72.4 & $100 \%$ & 5.1 & $100.00 \%$ & CP029543.1 \\
\hline$\square$ & Mycobacterium leprae Kyoto-2 DNA, complete genome & 36.2 & 1338 & $100 \%$ & 5.1 & $100.00 \%$ & AP014567.1 \\
\hline$\square$ & Mycobacterium leprae B $\mathrm{r} 4923$, complete genome sequence & 36.2 & 1338 & $100 \%$ & 5.1 & $100.00 \%$ & FM211192.1 \\
\hline$\square$ & Mycobacterium leprae cosmid B1170 & 36.2 & 36.2 & $100 \%$ & 5.1 & $100.00 \%$ & $\underline{\underline{u} 00010.1}$ \\
\hline$\square$ & Mycobacterium leprae cosmid L247 & 36.2 & 72.4 & $100 \%$ & 5.1 & $100.00 \%$ & $\underline{\mathrm{u} 00021.1}$ \\
\hline$\square$ & Mycobacterium leprae strain TN complete genome; segment 1/10 & 36.2 & 180 & $100 \%$ & 5.1 & $100.00 \%$ & AL583917.1 \\
\hline$\square$ & Mycobacterium leprae cosmid B998 DNA sequence & 36.2 & 36.2 & $100 \%$ & 5.1 & $100.00 \%$ & $\underline{\mathrm{L} 78829.1}$ \\
\hline$\square$ & Mycobacterium leprae cosmid B27 DNA sequence & 36.2 & 72.4 & $100 \%$ & 5.1 & $100.00 \%$ & $\underline{\text { L78817.1 }}$ \\
\hline$\square$ & Mycobacterium leprae cosmid B1229 DNA sequence & 36.2 & 36.2 & $100 \%$ & 5.1 & $100.00 \%$ & $\underline{\underline{778812.1}}$ \\
\hline
\end{tabular}

Gambar 2 Hasil Pensejajaran Sekuen Forward Primer dengan BLAST NCBI.

\begin{tabular}{|c|c|c|c|c|c|c|c|}
\hline & Description & $\begin{array}{c}\text { Max } \\
\text { score }\end{array}$ & $\begin{array}{ll}\text { Total } \\
\text { score }\end{array}$ & $\begin{array}{l}\text { Query } \\
\text { cover }\end{array}$ & $\underset{\text { value }}{\mathrm{E}}$ & Ident & Accession \\
\hline$\square$ & Mycobacterium leprae clone m305-17 RLEP repeat region & 42.1 & 42.11 & $100 \%$ & 0.083 & $100.00 \%$ & $\underline{\text { MF975707.1 }}$ \\
\hline$\square$ & Mycobacterium leprae clone m787-17 RLEP repeat region & 42.1 & 42.11 & $100 \%$ & 0.083 & $100.00 \%$ & $\underline{\text { MF975706.1 }}$ \\
\hline$\square$ & Mycobacterium leprae clone m809-17 RLEP repeat region & 42.1 & 42.11 & $100 \%$ & 0.083 & $100.00 \%$ & $\underline{\text { MF975705.1 }}$ \\
\hline$\square$ & Mycobacterium leprae Kyoto-2 DNA, complete genome & 42.1 & 15581 & $100 \%$ & 0.083 & $100.00 \%$ & AP014567.1 \\
\hline$\square$ & Mycobacterium leprae Br 4923 , complete genome sequence & 42.1 & 15581 & $100 \%$ & 0.083 & $100.00 \%$ & $\underline{F M 211192.1}$ \\
\hline$\square$ & Mycobacterium leprae cosmid L247 & 42.1 & 84.21 & $100 \%$ & 0.083 & $100.00 \%$ & $\underline{\mathrm{U} 00021.1}$ \\
\hline$\square$ & Mycobacterium leprae strain TN complete genome; segment 1/10 & 42.1 & $210 \quad 1$ & $100 \%$ & 0.083 & $100.00 \%$ & AL583917.1 \\
\hline$\square$ & Mycobacterium leprae cosmid B32 DNA sequence & 42.1 & 42.11 & $100 \%$ & 0.083 & $100.00 \%$ & $\underline{\underline{L 7} 8818.1}$ \\
\hline$\square$ & Mycobacterium leprae cosmid B27 DNA sequence & 42.1 & 84.21 & $100 \%$ & 0.083 & $100.00 \%$ & $\underline{\mathbf{L} 78817.1}$ \\
\hline$\square$ & Mycobacterium leprae cosmid B1723 DNA sequence & 42.1 & 42.11 & $100 \%$ & 0.083 & $100.00 \%$ & $\underline{\mathrm{L} 78825.1}$ \\
\hline & Gambar 3 Hasil Pensejajaran Sekuen Reverse Primer dengan & BLA & AST & $\Gamma \mathrm{NC}$ & CBI & & \\
\hline & Description & $\begin{array}{c}\text { Max } \\
\text { score }\end{array}$ & $\begin{array}{l}\text { Total } \\
\text { score }\end{array}$ & $\begin{array}{l}\text { Query } \\
\text { cover }\end{array}$ & $\begin{array}{c}E \\
\text { value }\end{array}$ & Ident & Accession \\
\hline$\square$ & Mycobacterium leprae clone m305-17 RLEP repeat region & 38.2 & 38.2 & $100 \%$ & 1.3 & $100.00 \%$ & MF975707.1 \\
\hline$\square$ & Mycobacterium leprae clone m787-17 RLEP repeat region & 38.2 & 38.2 & $100 \%$ & 1.3 & $100.00 \%$ & $\underline{\text { MF975706.1 }}$ \\
\hline$\square$ & Mycobacterium leprae clone m809-17 RLEP repeat region & 38.2 & 38.2 & $100 \%$ & 1.3 & $100.00 \%$ & MF975705.1 \\
\hline$\square$ & Mycobacterium leprae clone m1787-17 RLEP repeat region & 38.2 & 38.2 & $100 \%$ & 1.3 & $100.00 \%$ & $\underline{\text { MF975704.1 }}$ \\
\hline$\square$ & Mycobacterium leprae clone S473 Rlep repeat region & 38.2 & 38.2 & $100 \%$ & 1.3 & $100.00 \%$ & MF818035.1 \\
\hline$\square$ & Mycobacterium leprae strain MRHRU-235-G chromosome, complete genome & 38.2 & 38.2 & $100 \%$ & 1.3 & $100.00 \%$ & $\mathrm{CP029543.1}$ \\
\hline$\square$ & Mycobacterium leprae Kyoto-2 DNA, complete genome & 38.2 & 1411 & $100 \%$ & 1.3 & $100.00 \%$ & AP014567.1 \\
\hline$\square$ & Mycobacterium leprae Br 4923 , complete genome sequence & 38.2 & 1411 & $100 \%$ & 1.3 & $100.00 \%$ & FM211192.1 \\
\hline$\square$ & Mycobacterium leprae cosmid B1170 & 38.2 & 38.2 & $100 \%$ & 1.3 & $100.00 \%$ & $\underline{\mathrm{u} 00010.1}$ \\
\hline$\square$ & Mycobacterium leprae cosmid L 247 & 38.2 & 76.3 & $100 \%$ & 1.3 & $100.00 \%$ & $\underline{v 00021.1}$ \\
\hline
\end{tabular}

Gambar 4 Hasil Pensejajaran Sekuen Reverse Primer dengan BLAST NCBI

Hasil uji silang menggunakan BLAST NCBI menunjukkan bahwa sekuen pasangan primer maupun probe memiliki kemiripan $100 \%$ dengan M. leprae yang ditunjukkan dengan hasil query cover dan identifikasi $100 \%$. Pengujian adanya reaksi silang digunakan untuk memastikan bahwa sekuen pas angan primer serta probe memiliki kemungkinan kecil untuk berkomplementer dengan yang bukan sekuen gen target (Hung and Zhiping, 2016).

\section{Kesimpulan}

Diperoleh sekuen pasangan primerdan probe sekuen gen RLEP M. leprae yang memenuhi persyaratan sebagai primer dan probe dalam deteksi M. leprae berbasis q-PCR yaitu :forward primer : 5'GTGCGGCCACATTGACCA-3'; reverse primer : 3'-GGCTGTGCTGAAGGCGATATC-5' serta sekuen probe : 5'-CGCCGACACCTCAAGGCCA-3'. Sekuen pasangan primer dan probe ini dapat digunakan untuk kuantifikasi M. leprae menggunakan q-PCR setelah dioptimasi diujikan dengan menggunakan sampel klinis.

\section{Daftar Pustaka}

Arliny Y. Deteksi Mycobacterium leprae Menggunakan Teknik Polymerase Chain Reaction (PCR) Pada Spesimen Hapusan Mukosa Hidung Dan Sayatan Lesi Kulit Penderita Kusta Baru. Surabaya. 2003.

Arya, M., I.S. Shergill., M. Williamson, L. Gommersall, N. Arya and HR. Patel. Basic principles of real-time quantitative PCR. Expert Rev Mol Diagn (2). 2005 : 209-219. 
Bakker MI., Hatta M., Kwwenang A. Epidemiology of Leprosy Among Five Isolated Island In The Flores Sea Indonesia. Tropical Med Int Health. 2002 : 780.

Baxevanis, A.D. and B.F. Ouelette. Bioinformatics a practical guide to the analysis of genes and protein, 3rd edition. Wiley inters cience, $2000: 1-449$.

Bryceson A. D. M. \& Pfaltzgraff R. E.. Edinburgh: Churchill Livingstone . Leprosy, 3rd edition. Edinburgh: Churchill Livingstone. 1999 : 240, ISBN 0-443-03373-0.

Eling, D.K., Sasmito, R. Kurniawan and I. Muhimmah. Karakteristik Primer pada Polymerase Chain Reaction (PCR) untuk Sekuensing DNA. Seminar Nasional Informatika Medis (SNIMed) V 20146 Desember 2014 : 93-101.

Hewajuli, D.A. and Dharmayanti NLPI. Perkembangan teknologi reverse transcriptase Polymerase Chain Reaction dalam mendeteksi genom avian influenza. Balai Besar penelitian Veteriner, 2014 : 16-26.

Hung, J. and Z. Weng. Designing Polymerase Chain Reaction Primers Using Primer3Plus. Cold Spring Harbor Laboratory Press. 2016 : 821-826.

Donoghue. PCR Primer That Can Detect M. leprae in Low Levels. J. Med. Microbiol. 2001 : 177-182.

Kampke, T., M. Kieninger and M. Mecklenburg. Efficient primer design algorithms. Bioinformatics, vol. 17, no. 3. $2001: 214-25$.

Kementerian Kesehatan RI. Pusat data dan Informasi Kementerian Kesehatan RI. Jakarta. 2018.

Lorenz, T.C. Polymerase Chain Reaction : Basic protocol Plus Troubleshooting and Optimization Strategy. Journal of Visualized Experiments. $2012: 1-15$.

McMurray DN. Mycobacteria and Nocardia. In Baron S.; et al. Baron's Medical Microbiology (4th ed.). University of Texas Medical Branch. ISBN 978-0-9631172-1-2. 1996.

Murray, R. K., Granner, D. K., \& Rodwell, V. W. Biokimia harper (27 ed.). Jakarta: Buku Kedokteran EGC. 2002.

Narayanan S, Deshpande U; Deshpande. Whole-Genome Sequences of Four Clinical Isolates of Mycobacterium tuberculos is from Tamil Nadu, South India. Genome Announc. 1 (3). 2013 : 6-13.

Obraztsova OA1, Verbenko DA1, Karamova AE1, Semenova VG1, Kubanov AA1, Deryabin DG. The refinement of leprosy PCR diagnostics by the amplification of specie-specific repeated fragment of the Mycobacterium leprae genome. Klin Lab Diagn. 2018;63(8). 2018 : 511-516.

Rees RJW, Young DB. The microbiology of leprosy. Dalam : Hasting RC, editor. Leprosy. Edisi ke-2. Edinburg: Churchil Livingstone. 1994 : 49-83.

Sandri RC. \& Ida Maria Foschiani \& Maria Renata Sales Nogueira Costa \& Sara Nader Marta \& Marcos da Cunha Lopes Virmond. Early detection of M. leprae by qPCR in untreated patients and their contacts: results for nasal swab and palate mucosa scraping. European Journal of Clinical Microbiology \& Infectious Diseases. 2018.

Thermofisher. Real-time PCR handbook. Appliedbiosystem, 2016 : 2-68.

Viljoen, G.J., L.H. Nel and J.R. Crowther. Molecular Diagnostic PCR Handbook. Springer. 2005 : 1-260.

Yan Wen, Yan Xing, Lian Chao Yuan, Rong De Yang, Fu Yue Tan, Ying Zhang and Huan-Ying Li. Application of RLEP Real-Time PCR for Detection of M. leprae DNA in Paraffin-Embedded Skin Biopsy Specimens for Diagnosis of Paucibacillary Leprosy. Am. J. Trop. Med. Hyg., 90(3), 2014 : 524-529. 